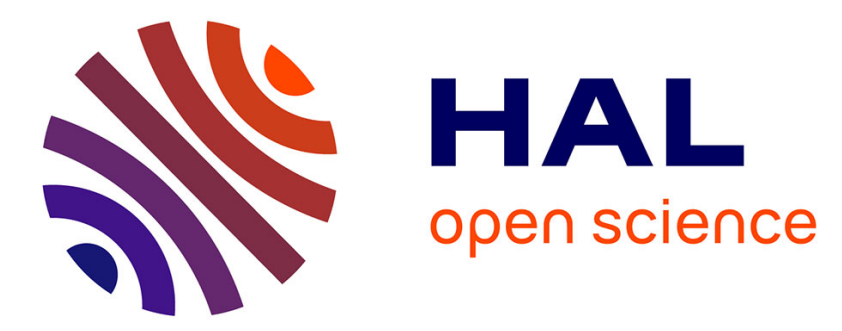

\title{
Managing Requirements: For an Integrated Approach from System Engineering to Project Management
}

Michel Malbert, Daniel Estève, Claude Baron, Philippe Esteban, Rui Xue

\section{To cite this version:}

Michel Malbert, Daniel Estève, Claude Baron, Philippe Esteban, Rui Xue. Managing Requirements: For an Integrated Approach from System Engineering to Project Management. IFIP International Conference on Advances in Production Management Systems (APMS), Sep 2014, Ajaccio, France. pp.142-149, 10.1007/978-3-662-44739-0_18 . hal-01284568

\section{HAL Id: hal-01284568 \\ https://hal.science/hal-01284568}

Submitted on 7 Mar 2016

HAL is a multi-disciplinary open access archive for the deposit and dissemination of scientific research documents, whether they are published or not. The documents may come from teaching and research institutions in France or abroad, or from public or private research centers.
L'archive ouverte pluridisciplinaire HAL, est destinée au dépôt et à la diffusion de documents scientifiques de niveau recherche, publiés ou non, émanant des établissements d'enseignement et de recherche français ou étrangers, des laboratoires publics ou privés. 


\title{
Managing requirements: for an integrated approach from system engineering to project management
}

\author{
Michel Malbert ${ }^{1}$, Daniel Estève ${ }^{2}$, Claude Baron ${ }^{2,3}$, Philippe Esteban ${ }^{2,4}$, and Rui Xue ${ }^{2,3}$ \\ ${ }^{1}$ Consultant, 24 rue Cartailhac,31000 Toulouse, France \\ michel.malberteoutlook.fr \\ ${ }^{2}$ CNRS, LAAS, 7 av. du colonel Roche, F-31400Toulouse, France \\ \{daniel.esteve, claude.baron, philippe.esteban, \\ rui.xue\}@laas.fr \\ ${ }^{3}$ Univ de Toulouse, INSA, LAAS, F-31400Toulouse, France \\ ${ }^{4}$ Univ de Toulouse, UPS, LAAS, F-31400Toulouse, France
}

\begin{abstract}
This paper puts forward several evolutions in methodological approaches to «project management». Firstly, it aims to bring closer the founding models of different engineering approachesincluding systems engineering and project management recommendations to allow fora greater continuity and enhanced management coherence,from beginning to end of the project. It focuses on operating a generic process, called DECWAYS, based on handling management requirements:(1)analyze the requirements to arrive at a complete inventory of the final product;(2)associate with each one of these requirements,an «indicator» setting a target objective for completion, supplemented by a risk function detailing the risk at hand based on the deviation relative to this target objective; (3)share and allocate the responsibility for requirements follow-up between the project team leaders; (4) organize and coordinate the follow-up of these indicators throughout the product development as proof of a good work management and,(5) finally, validate the total completion of the target objectivesthrough the final prediction/completion conformity of these indicators. Based on this, several operational recommendations are explained and the practicality of DECWAYS embodying these principles is demonstrated using an experimental example for the design/planning of an electronic key.
\end{abstract}

Keywords:System Engineering, Project Management, Collaborative Engineering

Introduction: In terms of «system »,innovation defines anissue which is very difficult to address and still open to methodological progress in the management of multidisciplinary and complexity, prerequisite for success at all levels of the innovation process: from project definition and design stages to the finished product'send of life cycle. This issue is thereforegrounded in all scientific and technical approaches built around this system innovation: «system engineering» which purports to formalize

adfa, p. 1, 2011.

(C) Springer-Verlag Berlin Heidelberg 2011 
and comprehend thedesign of complex systems; «project management » which aims to organizestep by step thesmooth operation of project development(or program development when several projects have to be coordinated); «collaborative engineering » which intends to facilitate, optimize communication between all actors and therefore contribute to meeting coordination needs... Naturally, to master the difficulties inherent in multidisciplinary,it is first assumed that these various inputs get progressively aligned through a single "integrated" approach. These alignments are being carried out and have already given rise to meetings and jointdocuments $[1,2,3]$ : they define a path of progressthrough terminologicaladjustments and a standardization of processes which will necessarily have to cut across various fields. This path is slow and arduous if only for the reason that it must be constructed on theoperational ground, that of the company... Here, a more conceptual path is being proposed to move forward: we intend to rely on an innovation process, a unique federating process built on managing «systems requirements» only: this overall system development-innovation process can be defined as the set of basic processesenabling us to organize and handle the full completion of specifications and requirements, from the product definition phase to the product's end of life cycle...Theprerequisite for success is that system requirements are complete in the sense that they have to address the whole innovationdevelopment process one intends to manage: for simplicity's sake it is assumed that these requirements can be presented in the form of a List (R1, R2...). Based on these considerations, DECWAYSpropose a complete innovative generic process build on the idea of sharing the requirements follow up between three specialized leaders (executing, controlling and planning), for structuring a permanent coordination. The presentation develop successively: the question of requirements to arrive at a complete inventory of the final product ; the association with each one of these requirements, an «indicator» setting a target objective for completion, supplemented by a risk function detailing the risk at hand based on the deviation relative to this target objective; the information system which organize and coordinate the follow-up of these indicators throughout the product development as proof of a good work management. Finally, we illustrate a first step of DECWAYS development on an experimental example for the design/planning of an electronic key.

\section{Requirements, the foundation for a «product» development follow- up process}

Requirements analysis is a 'critical' input at the start of an innovating project: based on the results of this analysis are all the prospective assessments thatwill play such an important part in the decision to launch the project... And it is worth underlining here how important these results are in the drawing up of a management methodology which on the basis of a complete inventory of these requirements, supports the definition of a consistent approach for product development construction and management.This approach consists of the following steps: (1) Analyze requirements to arrive at a complete inventory of the product life; (2) Associate with each one of these requirements an 'indicator' setting a completion target objective, supplemented by a risk function detailing the risk at hand as a function of the deviationrelative to that target objective; (3) Assign responsibility for requirements follow-up among the 
project team leaders; (4) Organize the follow-up of these indicators throughoutproduct development as proof of a soundwork management; (5) Finally, validate the full completion of the target objectives through the final prediction/completion conformityof these indicators.

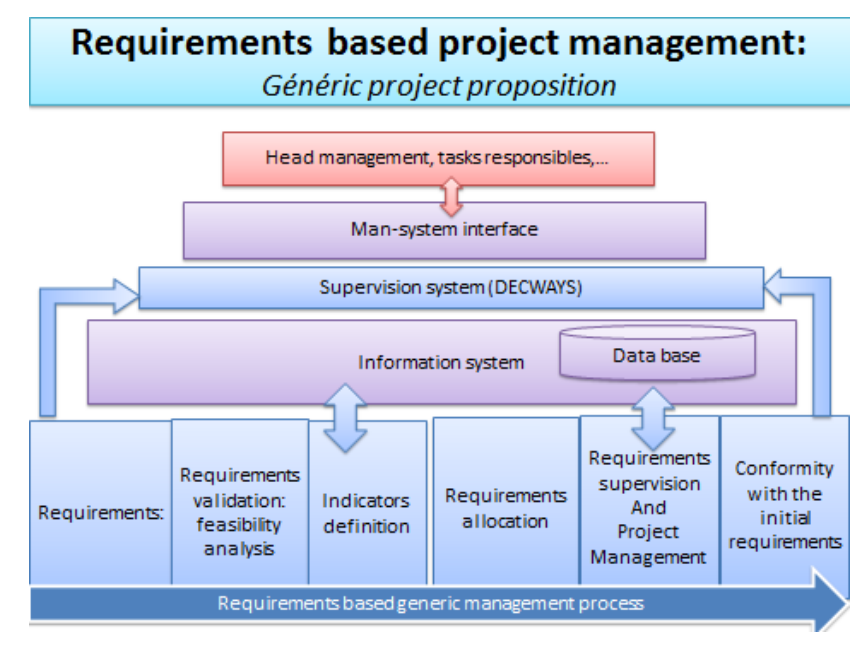

Fig. 1.Requirements-basedproject management

It appears that a requirements-based management lays the groundwork for a generic and complete project management process:generic because it does not implythat the nature of the project be specified as it may be a product or service;complete in the sense that it arises from an expression of ideas and objectives, through requirements and these target indicators, and finishes with an ending «selected» by the degree of conformity of the work result with these target objectives.Our ambition is to propose a «supervision system» associated with an «information system» related to this generic process whose assignment is to provide information and monitor automatically the evolution of "indicators" values throughout the work: thus emphasis is placed on the choice and quality of these indicators which more than ever must be fully defined, measurable, traceable and documented...

\section{Indicators}

In the approach put forward,indicators are directly associated with the requirementsof which they are proof throughout the development work. Under this assumption, their evolution from the initial situation to the target objectivemust be programmed using milestone target valuesin relation to the overall progress of the development work.Let us call $\Delta$ the deviation, at a given step t, between target value and current value, our proposal being to associate with this deviation a «risk function»for the project. In most cases, this function will pertain specifically to the corporate policy and will therefore be perfectly known to all actors. Our recommendation is that, at the very least, this function, which will be involved in the decisionchoices, be concerted at the start of the project and then have its full part in the decision phases. In practice it may take the simple form of a conventional risk scale, typically $\Delta$ be- 
tween 1 and 7, to calibrate the response between a low level of risk and a serious danger of failure.Indicators are simple and straightforward if they reflect requirements such as timelines, expenditures and certain performances, but they may also result from an aggregation of data selected following discussions to narrow down the number of parameters to be followedin the progress of the work or to express more clearly the corporate policy. These indicators will be computed online by the information system. In practice, the approach we recommend consists in collecting and recording during a step assessment (milestone) all indicator data on a «management dashboard» comparing the current reality with the «strategic dashboard» drawn up initiallyby the project management team. Any deviations found may then lead to management correctiveactions partly guided by the risk functions analysis. This point is key for a sound management of the project and actors must necessarily be coordinated to ensure pertinence, coherence and efficiency in their corrective choices. In these choices, the corporate policy plays a decisional role which should already be known to all, given the calibrations of risk functions selected for each requirement.One may question the genericity of the proposal as a function of specificities in the choice of certain preferred industrial management options: for example, can this approach be applied indifferently, for a «conventional top-down»management andan «agile» managementof project: in the latter case, the alignment of milestone deadlines and the need to factor in an added value foreach one does not call for a change in the approach: at each new step in the project breakdown, a limited number of selected requirements will guide in the management of the new step, once the results of the previous step have been achieved.

\section{Information system}

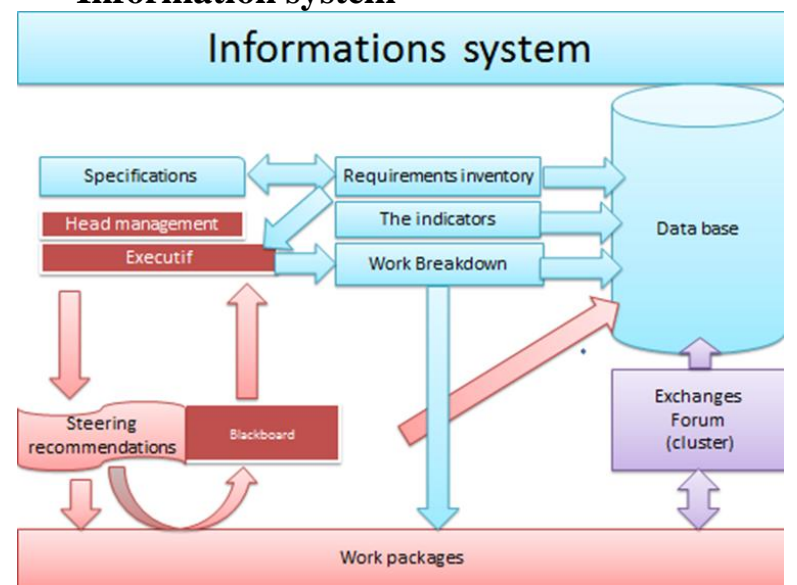

Fig. 2.Information system

During project development, a requirements-based management will basically consist infollowing up the indicators throughout the project life: thus any deviations in terms of completion between the current progress and the target objective initially defined by the requirements will be detected. Thus, looking at all the indicators (dashboards) one can accurately monitorthe evolution of the project and detect at the earliest any 
possible drift relative to the target objectives and possible errors in operational management: this can be achieved by programming milestones or alternatively, it may spontaneously follow a project management decision to intervene. For complex projects necessitating a task breakdown, task managers will receive their roadmaps on the basis of a project requirements assignment and will be able to organize their task developments in accordance with our recommendations. Together they will have to complete during the milestones their progress file stating to senior management any progress that has been recorded under their guidance.An information system is essential for the collection and storage of all useful data: organizational choices, target data, current data, management decisions and exchanges between the different actors.

\section{Supervision(DECWAYS)}

Improvingthe methods and tools in project management is an industrial imperativeclearly identifiedin the reviews dealing with assessment study: successes and failures of a large sample of projects. Here our ambition is to improve the dysfunction detection approach in project management and the ability of allproject actors to coordinate their involvement. The idea is to propose a structured path for the actions to be carried out byapportioning the requirements follow-up tasks between a defined number of managers and thus oblige the latter to structurallymake concerted decisions. This principle is supplementedby the choice, for project management, of a supervision system approach based on an automated detection of deviations or malfunctions during programmed management, by risk analysis in the choice or corrective decisions and by a systematic storage of all decisions made. This choice should facilitate implementationin practice since monitoring does not call for a modification of the tools already in usein companies but «only» to make them communicate towards the proposed procedures.These proposals lead in turn to the proposal of a new tool: DECWAYS. DECWAYS intends to provide the company with a method and a tool for supervision, coordination and decision support during the management of development projects:Supervision: this function is designed to detect and characterize systematically and automatically any erroneous trends and possible errors in design and management throughout project development.Coordination: this function is designed, following detection ofthe malfunction or deviation, to «oblige» the collegial body made up of a limited number of managersto consult each other on their structurally complementary points of view, andto propose a corrective consensus in accordance with the common objective of achieving success with theproject.Decision support: this function which aims to support the diagnosis of the cause for the difficulty encountered and to formulate a corrective approach which anticipates the compared « risks »of the different solutions proposed by the limited number of partners in charge.DECWAYS is built around aconventional supervision system architecture[4]: measurements are regularly obtained from the system and compared with reference values. Any deviations found can then be used to check the properfunctioning and detect possible «failures». But that can only be done if the reference values, that is the correct functioning model, are «fair». In practice,there exist two options: one is empirical based on value learning during periods of correct operation, the other relying on a theoretical model. In terms of project management, the model is neces- 
sarily theoretical: it results from an initial modeling which is predictive of the project progress.

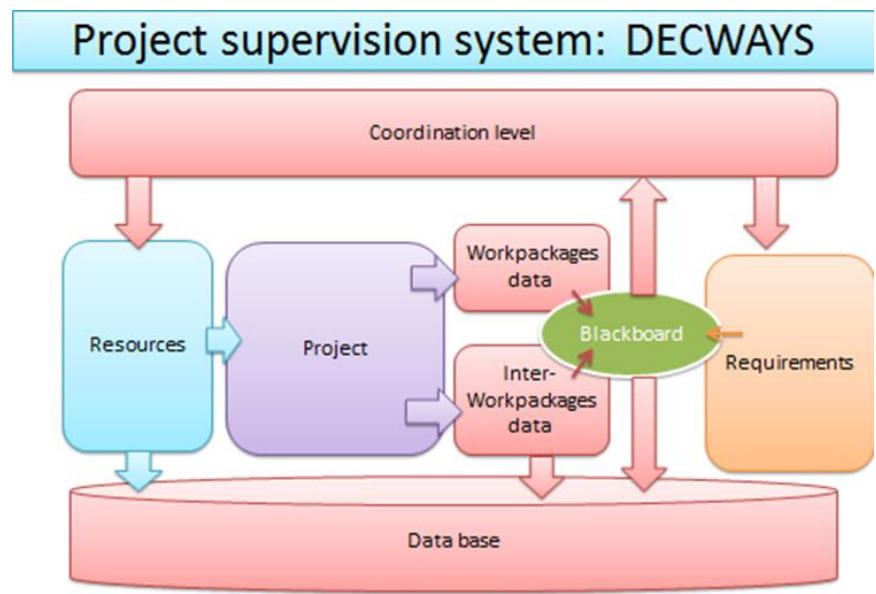

Fig. 3.Project supervision project: «DECWAYS »

\section{Example of DECWAYS implementation and application to the design of an electronic key}

Basic rules [5] condition the development of specialized tools furnishing supervision, coordination and decision support inproject management. However, it turns out that these expert rules are in part the result of work conducted within the framework of the contract ANR/ATLAS [6] in which the three salient features ofDECWAYS were being explored :supervision, coordination and decision supportthough the concept of risk functions associated with the deviations between current data and target objectives. A first result of this experiment: it is imperative that design and planning managers share the same Work Breakdown Structure (hereafter 'WBS') for the project. This structural framework formalizes and organizes exchange, coordination and decisionneeds shared at each level(milestones). A supervision software mockup [7] has been developed with an industrial support which validated the practicality of the approach. It is being investigated in depth in order to create a newDECWAYS toolincluding the previous proposals and puts forward a generalization of the notion of indicators inorder to take into account the strategic objective of standardization between system engineering andproject management processes. The toolATLAS has been investigated within the framework of an «electronic key» projectfollow-up for the automotive industry. Look at Fig. 4 below: it depicts at the instant considered,the logicbreakdown tree for theproject's system design with a review of possible solutionsin the case of a key-detector couple. The project management tree remains the same. This homomorphy results from the step-by-step construct logic reliant upon the generic process and illustrated in Fig. 5. 


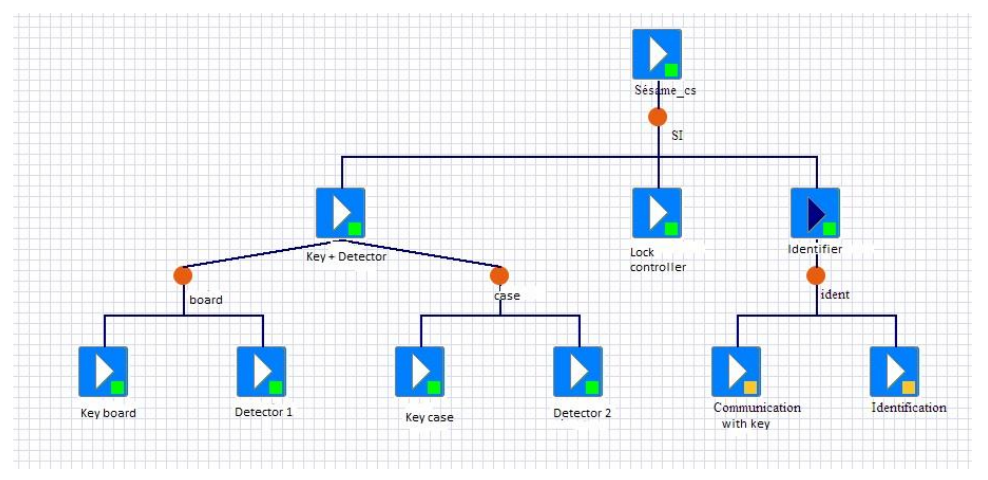

Fig. 4. - The electronic key project « Sésame»

The generic process relies on the general idea that it is possible, on the basis of the initial set of specifications and its embodiment in requirements and therefore inindicators under constraints, to draw up derivative specifications andrequirements for a group of subcontractors in charge of part of the project. Of course all this applies to the design as well as to managementand should not lead to any loss of information.Coupling design and management processes is achieved by pooling togethera number of indicators (allowing thus for the detection of any inconsistencies between the two parties) and sharing decisions (eg, the decision to define a subcontractor workpackagecalls for the approval by both partners as to the technical objectives and the means provided to reach them). Example of a situation handled by ATLAS: consider a joint design and management indicator, Nhthe total number of work hours toreach the objective assigned to a subcontracted workpackage. This value is set by the prime contractor and assigned as objective to be reached by the subcontractor's management. The subcontractor's design will assess this value and submit the result to his management colleague: in the event of a dispute they will either look fora solution acceptable to them or contact the prime contractor to negotiate a settlement.Indicator values are known at each tree node (nodes being depicted as small squares in Fig. 4). Therefore it is possible to know the state of the system at each tree node via the associated dashboard: this information along with the formalized collaboration between these two major functions "design" and "management" are both a diagnostic support and beyond, a decision support. Note that the dashboard associated with a node yields for an indicator the local value and the aggregate value fed from the tree branch concernedThis feature allows management to choose between several solutions the one which yields for example the best result for a key indicator.An operational prototype ATLAS has been drawn up and allows us to check $1 /$ the feasibility of the design - management coupling, 2/ the supportin choosing the right solutions for the electronic key problem, 3 / the relevanceof the choice of thin client-Web technology as an implementation environment. 


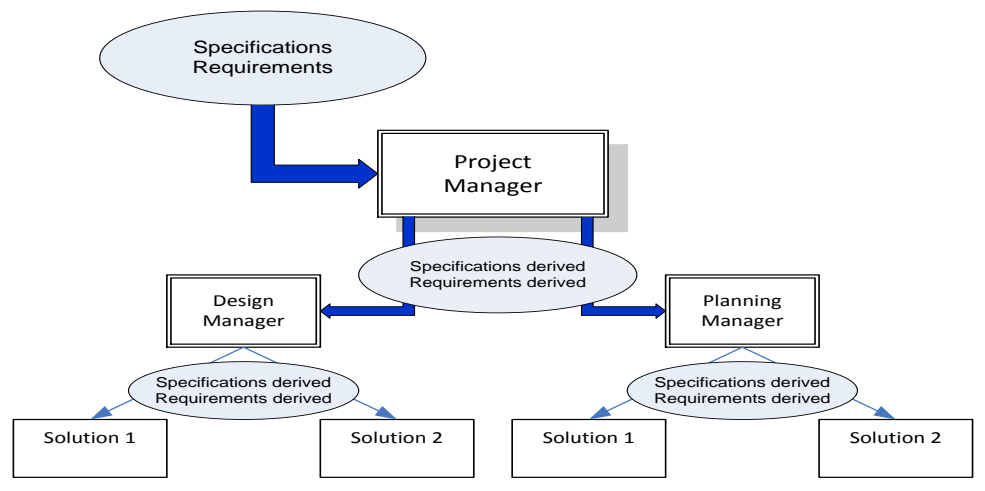

Fig. 5.-Tree construction principle

Conclusions: Improving the methods and tools for project management is an industrial imperative that has been clearly identified in the analyses dealing with assessment reviews, successes and failures of a large sample of projects. The aim of the proposals made in this paperis to improve coordination and cooperation between all project leaders. The idea relies on putting forward a generic process built on the thorough management of the system requirements which is then used to build up informationand supervision system referred to asDECWAYS. Thanks to a generalized follow-upof «indicators », this system supports automated detection of any deviations or malfunctions in the programmed management, risk analysis in the choice of corrective actions and systematic storage of these decisions... These proposals lead in turn to the proposedof anew tool DECWAYSwhich does not call for any modification of thetools alreadyin use by companies but "simply" to have them communicate (information system) towards the proposed procedures. A simple example of a first development shows the feasibility and confirms the interest of the approach.

\section{References}

1. A. Sharon, O. L. de Weck, et D. Dori, «Project management vs. systems engineering management: A practitioners' view on integrating the project and product domains », Syst. Eng., vol. 14, no 4, p. 427-440, 2011.

2. E. Conforto, M. Rossi, E. Rebentisch, J. Oehmen, et M. Pacenza, «Survey Report: Improving Integration of Program Management and Systems Engineering », MIT Consortium for Engineering Program Excellence, 2013.

3. «Systems Engineering - Project Management (SE - PM) Working Group - INCOSE Chesapeake Chapter Chesapeake Chapter of INCOSE». [Online]. Available on: http://www.incose-cc.org/2012/04/systems-engineering-project-management-se-pmworking-group/. [last consult: 27-feb-2014].

4. S.BONHOMME, E.CAMPO, D.ESTEVE, J.GUENNEC, « Methodology and tools for the design and verification of complex systems », IS'08, Varna, Sept 2008, pp.24-2-24-7

5. M. Malbert, D. Estève, C. Baron, R. Xue, P. Esteban «DECWAYS, une nouvelle étape dans les approches de la conduite de projet », LAAS-CNRS, 2014 (in press)

6. ATLAS « Aides et assisTances pour la conception, la conduite et leur coupLage par lesconnAissanceS », Contrat ANR programme «Technologies Logicielles »07-TLOG-00205, 2007-2011. 
